\title{
Undervalued N3-Coordination Revealed in the Cisplatin Complex with 2'-Deoxyadenosine-5'-Monophosphate by a Combined IRMPD and Theoretical Study
}

Barbara Chiavarino $^{1 *}$, Maria Elisa Crestoni ${ }^{1}$, Simonetta Fornarini ${ }^{1}$, Debora Scuderi ${ }^{2}$ and Jean-Yves Salpin ${ }^{3,4^{*}}$

1) Dipartimento di Chimica e Tecnologie del Farmaco, Università di Roma "La Sapienza", P.le A. Moro 5, I-00185 Roma, ITALY

2) LCP, Université Paris Sud Orsay, CNRS, Université Paris-Saclay, F-91405 Orsay, France

3) LAMBE, Université d'Evry Val d'Essonne, CEA, CNRS, Université Paris-Saclay, F91025, Evry, France

4) LAMBE, Université Cergy-Pontoise, Université Paris-Seine, F-91025, Evry, France

\section{Corresponding authors:}

Dr Barbara Chiavarino

e-mail: barbara.chiavarino@uniroma1.it

Dr Jean-Yves Salpin

e-mail: jeanyves.salpin@univ-evry.fr 


\section{Abstract}

The complex obtained by the reaction of cisplatin and $2^{\prime}$-deoxyadenosine- 5 '-monophosphate (5'-dAMP) in water has been isolated and detected by electrospray ionization mass spectrometry. The so-formed cis-[PtCl$\left.\left(\mathrm{NH}_{3}\right)_{2}\left(5^{\prime}-\mathrm{dAMP}\right)\right]^{+}$complex has been studied in detail by IR multiple photon dissociation (IRMPD) spectroscopy in two spectral ranges, namely $700-1900 \mathrm{~cm}^{-1}$ and $2800-3800 \mathrm{~cm}^{-1}$ backed by quantum chemical calculations at the B3LYP/LACV3P/6-311G** level of theory.

In agreement with computational results, the vibrational spectroscopic characterization of the $c i s-\left[\mathrm{PtCl}\left(\mathrm{NH}_{3}\right)_{2}\left(5^{\prime}-\mathrm{dAMP}\right)\right]^{+}$shows that the sampled ionic population comprises two major isomers, differentiated in the $\mathrm{X}-\mathrm{H}$ stretching region by their distinct fragmentation pattern. One of these species presents coordination of the platinum moiety at the N3 position of adenine whereas in the second one platinum is bound at the N1 position of adenine. IRMPD kinetics have allowed an estimation of their relative proportions. Surprisingly, the most abundant component of $c i s-\left[\mathrm{PtCl}\left(\mathrm{NH}_{3}\right)_{2}\left(5^{\prime}-\mathrm{dAMP}\right)\right]^{+}$results to be the $\mathrm{N} 3$ isomer, though slightly less stable than the other potential isomers in the gas phase. In contrast, the lowest energy species, namely the one showing cisplatin binding to the N7 position of adenine, seems to be the one less represented in the sampled ion population. These findings suggest that the reaction of cisplatin with 5'-dAMP is governed by the kinetics of the process occurring in solution rather than by thermodynamic factors. 


\section{Introduction.}

Cisplatin (cis-diamminedichloroplatinum(II)) has revolutionized anticancer therapy and is nowadays one of the most widely prescribed drug for many cancers, including testicular, ovarian, head, and neck cancer. ${ }^{1}$ Although its mechanism of action has not yet been fully characterized, it is generally accepted that the therapeutic activity of cisplatin proceeds through metal coordination to nucleobases leading to crosslinks within DNA, which inhibit replication and transcription processes, and cause ultimately cell apoptosis. ${ }^{2-5}$

It has been shown that the N7 position of guanine residues represents the most favored binding site of cisplatin ${ }^{6}$, and that the interstrand or intrastrand crosslinks generally contain at least one guanine residue. Studies on the interactions of cisplatin with the model mononucleotide 2'-deoxyguanosine-5'-monophosphate (5'-dGMP) confirm this finding. In solution, it has been shown for example that in the $c i s-\left[\mathrm{Pt}\left(\mathrm{NH}_{3}\right)_{2}\left(5^{\prime} \text {-dGMP-H) }\right]^{+}\right.$complex, the nucleotide forms a chelate complex by the N7 and an O atom of the phosphate group, with an anti orientation of the nucleobase. ${ }^{7,8}$ Also our own infrared multiple photon dissociation (IRMPD) studies characterizing the structure of the platinum complexes in the gas phase 9,10 confirm the very strong affinity of cisplatin towards the N7 atom, as well as the macrochelate nature of $c i s-\left[\mathrm{Pt}\left(\mathrm{NH}_{3}\right)_{2}\left(5^{\prime}-\mathrm{dGMP}-\mathrm{H}\right)\right]^{+}$complexes.

Besides guanine, the formation of crosslinks may also involve the adenine nucleobase. ${ }^{11}$ However, our recent IRMPD study points to a totally different coordination scheme for this nucleobase. As a matter of fact, the IRMPD spectrum of the cis-[PtCl( $\left.\left(\mathrm{NH}_{3}\right)_{2}(\mathrm{~A})\right]^{+}$complex (where $\mathrm{A}$ is adenine) is consistent with the presence of two major isomers involving platination at either N1 or N3 centers of adenine. ${ }^{9}$

In the present contribution, we continue the structural characterization of ionic complexes between cisplatin and biological targets such as the DNA building blocks by isolating them in 
the gas phase $\mathrm{g}^{9,10,12,13}$, and extend our study to the interactions of cisplatin with $2^{\prime}$ deoxyadenosine-5'-monophosphate (5'-dAMP).

Figure 1 displays the structure of 5'-dAMP with the conventional atom numbering.

$<$ Figure 1 >

Moving from the simple adenine nucleobase to the mononucleotide, the possible binding sites of cisplatin increase. In addition to adenine, platinum may also interact with the oxygen(s) of the phosphate group and with the hydroxyl group of the 2'-deoxyribose moiety. The aim of this study is to determine if increasing the size of the DNA building block will have an effect on the coordination site of adenine. To this end, we exploited electrospray ionization (ESI) coupled to ion trap mass spectrometry (either Paul type ion trap or Fourier transform ion cyclotron resonance, FT-ICR, mass spectrometry) to mildly transfer the complexes generated in solution into the gas phase where they are mass-analyzed and sampled by IRMPD spectroscopy. The ensuing vibrational signatures are interpreted with the support of theoretical DFT calculations. To perform IRMPD spectroscopy, mass spectrometry is interfaced with the output of tunable and intense IR radiation sources as already well documented. ${ }^{14-17}$

\section{Experimental}

\subsection{Materials}

Cisplatin and 5'-dAMP were research grade products from commercial sources (SigmaAldrich s.r.l. Milan, Italy) used without further purification. To generate the complexes of interest, an aqueous solution of cisplatin ca. $1 \cdot 10^{-3} \mathrm{M}$ was allowed to stand overnight. Mixing 
with a 5'-dAMP solution and appropriate dilution with water yielded the final solution of the two analytes in isomolar ratio and concentration of $5 \cdot 10^{-5} \mathrm{M}$.

\subsection{IRMPD experiments}

The complex of interest has been obtained as gaseous species by ESI of a water solution prepared as described. Typical ESI conditions were a flow rate of 2-4 $\mu \mathrm{L} / \mathrm{min}$, capillary spray voltage at $-3.8 \mathrm{kV}$, nebulizer at $15 \mathrm{PSI}$, drying gas flow at $5 \mathrm{~L} / \mathrm{min}$, and drying gas temperature at $300^{\circ} \mathrm{C}$.

Two distinct energy ranges were considered for IRMPD experiments. First, the vibrational modes associated with the $\mathrm{XH}(\mathrm{X}=\mathrm{C}, \mathrm{N}, \mathrm{O})$ stretches were investigated by recording IRMPD spectra in the $2800-3800 \mathrm{~cm}^{-1}$ frequency range. To this purpose, an optical parametric oscillator/amplifier (OPO/OPA, LaserVision) laser system coupled to a Paul ion trap mass spectrometer (Esquire 6000+, Bruker Daltonics), has been employed as described previously. ${ }^{18,19}$ The typical output energy from the OPO/OPA laser operated at $10 \mathrm{~Hz}$ was 20$25 \mathrm{~mJ} /$ pulse. In the trap, ions were accumulated for $10 \mathrm{~ms}$ and then mass-selected prior to IR irradiation. IRMPD spectra were recorded setting the irradiation time at $0.5 \mathrm{~s}$. Photofragmentation kinetics involved irradiation times varying from 0.3 to 20 s. Secondly, IRMPD spectra were recorded in the fingerprint region (700-1900 $\left.\mathrm{cm}^{-1}\right)$ using the beamline of the free electron laser (FEL) of the Centre Laser Infrarouge d'Orsay (CLIO). For the present study, the electron energy of the FEL was set at 36 and $45 \mathrm{MeV}$ in two distinct runs, to optimize the laser power in the frequency region of interest. The FEL beamline is coupled with a hybrid FT-ICR tandem mass spectrometer (APEX-Qe Bruker) equipped with a $7.0 \mathrm{~T}$ actively shielded magnet and a quadrupole-hexapole interface for mass-filtering and ion accumulation, under control by the commercial software APEX 1.0. Mass-selection of the complex under study was performed in the quadrupole and ions were accumulated in the 
hexapole containing argon buffer gas for $0.5 \mathrm{~s}$ for collisional cooling prior to their transfer into the ICR cell. The isolated charged complexes were then irradiated for $250 \mathrm{~ms}$ with the IR FEL light, after which the resulting ions are mass-analyzed. ${ }^{20,21}$

IRMPD spectra are obtained by plotting the photofragmentation yield $\mathrm{R}(\mathrm{R}=$ $\ln \left[I_{\text {precursor }} /\left(I_{\text {precursor }}+\Sigma I_{\text {fragment }}\right)\right]$, where $I_{\text {precursor }}$ and $I_{\text {fragment }}$ are the integrated intensities of the mass peaks of the precursor and of the fragment ions, respectively) as a function of the frequency of the IR radiation. ${ }^{20}$

\subsection{Computational Details}

Molecular orbital calculations were carried out using the B3LYP density functional, ${ }^{22,23}$ as implemented in the Gaussian-09 set of programs. ${ }^{24}$ The different structures considered have been optimized using the $6-311 \mathrm{G}^{* *}$ basis set, without any symmetry constraint. In order to describe the metallic center, we used the Los Alamos effective core potential (ECP) in combination with the LACV3P** basis set. $^{25-27}$ Harmonic vibrational frequencies were estimated at this level to characterize the stationary points as local minima or saddle points, and to estimate the zero-point vibrational energy (ZPE) corrections. In the perspective of studying bigger systems, B3LYP/6-31G** calculations have been also performed, Pt being described either with the SKBJ (Stevens, Krauss, Basch, Jasien) ECP+basis $\operatorname{sets}^{28}$ or the LANL2DZ approach. ${ }^{25-27}$ It turned out that both the relative energies and vibrational spectra are similar, regardless of the pseudo-potential and basis sets used to perform the calculations. Consequently, these two alternate approaches could be used confidently for bigger complexes. The infrared absorption spectra of the various structures were calculated within the harmonic approximation. All calculated frequencies were scaled by a factor of 0.974 in the fingerprint region and by 0.957 in the $\mathrm{X}-\mathrm{H}$ stretch region for a better agreement with the experimental spectrum. These scaling factors were previously adopted for the related, simpler complex cis- 
$\left[\mathrm{PtCl}\left(\mathrm{NH}_{3}\right)_{2} \mathrm{~A}\right]^{+}$with good results. ${ }^{9}$ However, a distinct treatment is required for the IR modes involving the phosphate group. As reported in previous papers about phosphates ${ }^{29-31}$, phosphorylated amino acids ${ }^{32-34}$ and nucleotides ${ }^{10,35-40}$, the scaling factors normally suitable for the vast majority of vibrational modes are found to be systematically too low for the stretching modes involving $\mathrm{P}-\mathrm{O}$ bonds belonging to the phosphate group (as well as $\mathrm{SO}$ and NO bonds in other contexts ${ }^{41-45}$ ), when compared with the experimental frequencies.

Examples reporting phosphate $\mathrm{P}-\mathrm{O}$ and $\mathrm{P}=\mathrm{O}$ stretches for different systems have indicated that an appropriate scaling factor for the calculated harmonic frequency of these modes should be close to or even greater than one. ${ }^{32-40}$ In some studies, 'usual' scaling factors were adopted above $1300-1350 \mathrm{~cm}^{-1}$ while a using scaling factor equal or slightly above 1 for calculated vibrations below $1300 \mathrm{~cm}^{-1}$, namely the region of phosphate $(\mathrm{P}-\mathrm{OH}, \mathrm{P}=\mathrm{O}$ and $\mathrm{P}-\mathrm{OC})$ stretches. ${ }^{36,37,39}$ In the present study we decided to use the same strategy as the one used for cis- $\left[\mathrm{PtCl}\left(\mathrm{NH}_{3}\right)_{2}(\mathrm{dGMP})\right]^{+}$complexes, by employing a scaling factor of 0.974 for all IR frequencies in the fingerprint range, and no scaling factor (that is 1) only for the frequencies involving the $\mathrm{P}=\mathrm{O}, \mathrm{P}-\mathrm{OH}$ and $\mathrm{P}-\mathrm{OC}$ stretches of the phosphate group. ${ }^{10}$

Throughout this paper total energies are expressed in Hartrees and relative energies in $\mathrm{kJ}^{\mathrm{mol}}{ }^{-}$ ${ }^{1}$. For the sake of simplicity, the basis set used will be referred to as $6-311 \mathrm{G}^{* *}$ henceforth. Detailed geometries (Cartesian coordinates) of all the structures mentioned in this paper are available from the authors upon request.

\section{Results and Discussion}

Formation of the $c i s-\left[\mathrm{PtCl}\left(\mathrm{NH}_{3}\right)_{2}\left(5^{\prime}-\mathrm{dAMP}\right)\right]^{+}$complex is observed soon after mixing the two solutions containing either cisplatin or 5'-dAMP, respectively. Under usual ESI conditions, a pronounced signal is observed at $\mathrm{m} / \mathrm{z}$ 594-598, consistent with the formation of cis- 
$\left[\mathrm{PtCl}\left(\mathrm{NH}_{3}\right)_{2}\left(5^{\prime} \text {-dAMP }\right)\right]^{+}$, together with other species containing cisplatin bound to various units or fragments of 5'-dAMP, as reported previously. ${ }^{9}$

The complete isotopic cluster at $\mathrm{m} / z$ 594-598 corresponding to the cis- $\left[\mathrm{PtCl}\left(\mathrm{NH}_{3}\right)_{2}\left(5^{\prime}\right.\right.$ $\mathrm{dAMP})]^{+}$complex was isolated in the cell of the mass spectrometer to be submitted to IRMPD spectroscopy. The lower panel of Figure 2 reports the experimental IRMPD spectrum obtained in the X-H stretching region, namely $2850-3700 \mathrm{~cm}^{-1}$. The first important finding we observed while studying the IRMPD process in this particular energy range is that the photofragmentation pattern of $c i s-\left[\mathrm{PtCl}\left(\mathrm{NH}_{3}\right)_{2}\left(5^{\prime}-\mathrm{dAMP}\right)\right]^{+}$is different when one inspects different absorption bands. This behaviour is indicative of the simultaneous presence of at least two different isomers. The first photofragmentation pattern, observed in correspondence with the features at 3493 and $3381 \mathrm{~cm}^{-1}$, occurs along four different channels (Figure $3 \mathrm{~b}$ ). There is the loss of an ammonia molecule to generate the cluster at $m / z$ 577-581 and the loss of $\mathrm{HCl}$ to yield the $c i s-\left[\mathrm{Pt}\left(\mathrm{NH}_{3}\right)_{2}\left(5^{\prime}-\mathrm{dAMP}-\mathrm{H}\right)\right]^{+}$complex (cluster at $\mathrm{m} / z$ 558-562). The two other fragmentation channels involve the cleavage of the N-glycosidic bond presumably leading to either $\left[\mathrm{PtCl}\left(\mathrm{NH}_{3}\right)(\mathrm{A})\left(\mathrm{HPO}_{3}\right)\right]^{+}$(cluster at $m / z$ 461-465, where the presence of the chlorine atom is confirmed by the isotopic pattern) or cis- $\left[\mathrm{PtCl}\left(\mathrm{NH}_{3}\right)_{2}(\mathrm{~A})\right]^{+}$(cluster at $\mathrm{m} / \mathrm{z}$ 398-403), and $\left[\mathrm{PtCl}\left(\mathrm{NH}_{3}\right)(\mathrm{A})\right]^{+}$at $m / z$ 381-385 (A stands for the adenine nucleobase, $\mathrm{C}_{5} \mathrm{H}_{5} \mathrm{~N}_{5}$, to be consistent with ref. ${ }^{9}$ ). In this first photofragmentation pattern the adenine residue is always present in all the fragment ions. Conversely, the two major fragment ions observed in correspondence with the absorptions at 3435 and $3546 \mathrm{~cm}^{-1}$ are rather due to the loss of the adenine nucleobase (A) yielding the cluster at $\mathrm{m} / \mathrm{z} 459-463$, and the one at $\mathrm{m} / \mathrm{z} 441-445$, the latter involving also loss of a water molecule. It is worth noting that in the two bands at 3435 and $3546 \mathrm{~cm}^{-1}$ one finds also minor photofragments due to the loss of ammonia and/or $\mathrm{HCl}$. (Figure 3c). The other bands, especially the intense feature at $3663 \mathrm{~cm}^{-1}$, present both 
photofragmentation channels (Figure 3a, Figure S1 and Table S1). In order to confirm that the two different photofragmentation channels observed indeed correspond to at least two different isomers in the sampled ion mixture, we first compare the IRMPD spectrum with the calculated IR spectra of candidate structures for the $c i s-\left[\mathrm{PtCl}\left(\mathrm{NH}_{3}\right)_{2}\left(5^{\prime} \text {-dAMP }\right)\right]^{+}$complex. As previously underlined, 5'-dAMP presents different platinum coordination sites. The N1, N3 and N7 positions of adenine are possible platination sites, but also the phosphate group may bind to the cis- $\left[\mathrm{PtCl}\left(\mathrm{NH}_{3}\right)_{2}\right]^{+}$moiety. In particular, binding with a phosphate oxygen atom may be consistent with the observed photofragmentation channel involving adenine loss. However, as reported in the former study of the cisplatin interaction with nucleobases, the IRMPD spectrum of the cis-[PtCl$\left.\left(\mathrm{NH}_{3}\right)_{2}(\mathrm{~A})\right]^{+}$complex pointed to the presence of two major isomers with metal binding to either the $\mathrm{N} 1$ or $\mathrm{N} 3$ atom of adenine, both showing the same photofragmentation mass-spectrum. $^{9}$

Calculations have therefore been performed taking into account all potential isomers, with cis$\left[\mathrm{PtCl}\left(\mathrm{NH}_{3}\right)_{2}\right]^{+}$coordinated to $\mathrm{N} 1, \mathrm{~N} 3, \mathrm{~N} 7$ adenine positions, as well as to the phosphate group. These examined complexes present a highly flexible character so that multiple conformers within each family of isomers need to be considered. Major differences concern the rotation of the nucleobase about the $\mathrm{N}$-glycosidic bond and the ribose ring-puckering. The so-called syn (anti) conformation relates to all the structures where the A residue is oriented towards (away from) the phosphate group. Regarding the sugar ring-puckering, optimization of the different forms resulted in various sugar conformations. A complete scheme with all the species investigated (showing relative free energies, coordination site, sugar arrangement, orientation of the adenine unit, and intramolecular hydrogen bonds) is provided in the Supporting Information.(Figure S2 - Table S2) 
First, one has to emphasize that, regardless of the interaction sites, the most stable forms systematically correspond to macrochelate structures resulting from the simultaneous interaction of the metal with the adenine residue and the phosphate group. Comparing the relative free energies calculated at $298 \mathrm{~K}$ for each individual family of isomers, the global minimum corresponds to a conformer with metal coordination at the N7 position (Table S2.) However, also N1 isomers have comparable stability. In fact, the most stable N1 conformer lies only $3.8 \mathrm{~kJ} \cdot \mathrm{mol}^{-1}$ higher in energy with respect to the most stable N7 one. Interaction with the $\mathrm{N} 3$ center results in slightly less stable macrochelate forms $(+10.6 \mathrm{~kJ} / \mathrm{mol})$. On the other hand, attachment of platinum at a phosphate oxygen atom (PO) gives rise to isomers lying much higher in energy, the most stable PO conformers being located at $57.3 \mathrm{~kJ} \mathrm{~mol}^{-1}$ above the global minimum. Figure 2 reports the calculated spectra of the most stable or representative conformer for each family of isomers, henceforth simply named as N7, N1, N3, and PO, indicative of the platinum coordination site.

Comparing the experimental spectrum in the $\mathrm{XH}$ stretching range with the calculated spectra gathered in Figure 2 and in Figures S3-S6 in the supporting information where two other calculated spectra for each isomer are reported as well, it is possible to observe that the major absorption at $3663 \mathrm{~cm}^{-1}$, highlighted in green, is matched by a band appearing in all structures platinated on the adenine ring, namely N1, N3 and N7. Optimized PO structures show absorption in this region that is either appearing at slightly higher frequency or is split in two bands, as shown in Figure S6. Interestingly, the band at $3663 \mathrm{~cm}^{-1}$ presents all photofragmentation channels previously described and should then include multiple isomers. For N1, N3 and N7 species, it combines both the PO-H stretch (in a 'free' state, namely not involved in hydrogen bonding) and the O3'-H stretch (computed at 3666-3672 and 3664- 
$3665 \mathrm{~cm}^{-1}$ respectively), that are active at closely spaced frequency in all the adenine ligated complexes.

The two bands at 3435 and $3546 \mathrm{~cm}^{-1}$, emphasized in blue (and characterized by the prominent loss of adenine in the IRMPD process), match only with the calculated spectra of N3 isomers (as also reported in Figure S4 on the supporting Information) and correspond to the symmetric and asymmetric $\mathrm{NH}_{2}$ stretching modes expected at 3434 and $3557 \mathrm{~cm}^{-1}$, respectively. These same vibrational modes are calculated at $\sim 3388$ and $3509 \mathrm{~cm}^{-1}$ for both $\mathrm{N} 1$ and N7 isomers and can thus account for the experimental bands at 3381 and $3493 \mathrm{~cm}^{-1}$, respectively (Figure 2, S3 and S5). These features, underlined in yellow, are characterized by the common loss of $\mathrm{NH}_{3}$ and $\mathrm{HCl}$ as major fragmentation paths.

With regard to PO conformers, in no one case is the calculated IR spectrum compatible with either pair of absorptions characteristic of a common isomer, namely the bands at 3381/3493 $\mathrm{cm}^{-1}$ or $3435 / 3546 \mathrm{~cm}^{-1}$ (Figure 2 and S6). Indeed, the absorptions at 3493 and $3546 \mathrm{~cm}^{-1}$ are never found in the IR spectra of PO isomers. Furthermore, the band calculated at $3464 \mathrm{~cm}^{-1}$, corresponding to the asymmetric $\mathrm{NH}_{2}$ stretching modes for the $\mathrm{PO}$ isomer, is not revealed in the IRMPD experiment.

Because these different frequencies are isomer specific, one can use IRMPD kinetics to probe the relative population of the isomeric species. ${ }^{46-51}$ First, IRMPD kinetics were performed at the frequency of $3663 \mathrm{~cm}^{-1}$. The results, presented in Figure 4, are plotted recording the decay of the total abundance of the whole isotopic cluster of the precursor ion, namely $I_{\text {precursor }} /$ $\left(I_{\text {precursor }}+I_{\text {fragment }}\right)$, where $I_{\text {precursor }}$ and $I_{\text {fragment }}$ are the integrated intensities of the mass peaks of the precursor and of the fragment ions, respectively, as a function of the laser irradiation time. At $3663 \mathrm{~cm}^{-1}$, nearly complete depletion of the precursor ion abundance, approximately $96 \%$, is observed and the kinetics conform to a neat exponential decay. The almost complete 
depletion indicates also that there is a good overlap of the IR beam with the ion cloud in our experimental setup. Based on this evidence and considering that this frequency is IR active for all N1, N3 and N7 isomers as well as PO conformers, the practically complete depletion of the precursor ion is indicative that all the species present in the sampled ion mixture undergo IRMPD in the $\mathrm{XH}(\mathrm{X}=\mathrm{C}, \mathrm{N}, \mathrm{O})$ stretching region examined. The absence of bands for (a)symmetric $\mathrm{NH}_{2}$ stretching modes expected from the $\mathrm{PO}$ isomers allows us to discard this family of isomers as possible candidates, in agreement with their relatively high free energy. Also shown in Figure 4, the photofragmentation kinetics studied at $3435 \mathrm{~cm}^{-1}$, corresponding to an absorption present only in N3-ligated complexes, conform to a monoexponential decay. However, in this case, the depletion of the precursor ion is not complete, ending with an unreactive fraction of $48 \%$. Thus, a contribution of approximately $52 \%$ can be estimated for N3 species. The kinetics recorded at $3493 \mathrm{~cm}^{-1}$, pertaining to an absorption common to both $\mathrm{N} 1$ and N7 family of isomers, do not reach a plateau even after 20 seconds of laser irradiation time (Figure 4). At this frequency the extrapolation of exponential decay reveals an unreactive fraction of approximately $60 \%$. In conclusion, the IRMPD experiments in the X-H stretching region allow asserting that the ionic population representing the $c i s-\left[\mathrm{PtCl}\left(\mathrm{NH}_{3}\right)_{2}\left(5^{\prime}-\mathrm{dAMP}\right)\right]^{+}$ complex may include up to three families of different isomers. The most abundant is the N3 isomer, characterized by a photofragmentation channel mainly associated with adenine loss. Because the metal is directly bound to an adenine nitrogen atom, dissociation of the nucleobase is somewhat unexpected. This unanticipated fragmentation channel may find an explanation considering the proximity of $c i s-\left[\mathrm{PtCl}\left(\mathrm{NH}_{3}\right)_{2}\right]^{+}$to the sugar and phosphate units, that can assist the loss of adenine by an intramolecular nucleophilic attack at the metal. The spectrum calculated for N3 and depicted in Figure 2 also shows two absorptions at 3295 and $3348 \mathrm{~cm}^{-1}$, attributed to asymmetric stretching of $\mathrm{N}-\mathrm{H}$ bonds within $\mathrm{NH}_{3}$ and $\mathrm{N}^{\prime} \mathrm{H}_{3}$ 
ligands, respectively, which can account for the experimental signals at 3283 and $3347 \mathrm{~cm}^{-1}$. Finally, two bands computed at 3214 and $3235 \mathrm{~cm}^{-1}$ are not observed in the experiment. However, these features are due to N-H stretching modes of a group involved in a hydrogen bond with the phosphoric functionality. It is well documented in the literature that X-H stretching modes involved in hydrogen bonding are hardly observed when the photofragmentation process requires more than one photon to reach the threshold fragmentation energy. ${ }^{52-55}$ Together with a major fraction of N3, the other species contributing to the observed IRMPD spectrum may include N1 and N7 isomers, characterized by comparable stability. The IRMPD experiment in the X-H stretching region does not allow to make an explicit assignment. In fact, the most stable conformers of both N1 and N7 families present quite comparable vibrational signatures (see Figure 2) if one excludes the PO-H stretching mode involved in a hydrogen bond with the sugar ring oxygen and computed at $3261 \mathrm{~cm}^{-1}$, but not observed experimentally probably for the reasons just mentioned above. Consequently, in order to gain a more detailed characterization of the cis- $\left[\mathrm{PtCl}\left(\mathrm{NH}_{3}\right)_{2}\left(5^{\prime}-\right.\right.$ $\left.\mathrm{dAMP}^{+}\right]^{+}$ion population, IRMPD spectra have been recorded also in the fingerprint range and compared to the calculated IR spectra of the same exemplary N7, N1 N3 and PO isomers, as reported in Figure 5.

The experimental IRMPD spectrum of the cis-[PtCl( $\left.\left(\mathrm{NH}_{3}\right)_{2}\left(5^{\prime}-\mathrm{dAMP}\right)\right]^{+}$complex, recorded between 700 and $1900 \mathrm{~cm}^{-1}$, is very rich and presents many distinct features, namely at 923 , 958, 1100, 1271-1340 and 1600-1648 $\mathrm{cm}^{-1}$ (Figure 5a). Other weaker bands are found at 870, $1042,1164,1417$ and $1480 \mathrm{~cm}^{-1}$. Clearly, this fingerprint domain presents a highly complex pattern, but unlike what was observed in the $\mathrm{X}-\mathrm{H}$ stretch region, the photofragmentation pattern of the cis- $\left[\mathrm{PtCl}\left(\mathrm{NH}_{3}\right)_{2}\left(5^{\prime}-\mathrm{dAMP}\right)\right]^{+}$complex is not wavelength-dependent in the fingerprint. Comparing the calculated spectra with the experimental one, we can easily 
exclude the presence of the PO family in the ionic cis- $\left[\mathrm{PtCl}\left(\mathrm{NH}_{3}\right)_{2}\left(5^{\prime} \text {-dAMP }\right)\right]^{+}$adduct under examination, confirming the previous evidence obtained in the $\mathrm{X}-\mathrm{H}$ stretching region. In particular, we note that the most active band at $1173 \mathrm{~cm}^{-1}$ in the IR spectrum of the PO isomer, associated with the $\mathrm{P}=\mathrm{O}-\mathrm{Pt}$ stretching, appears in a quite flat region in the experimental spectrum. Focusing on the three isomers bearing the $\left(\mathrm{NH}_{3}\right)_{2} \mathrm{PtCl}^{+}$moiety bound to adenine, the best fit between the experimental spectrum and the calculated ones pertains to the N1 isomer. However, the calculated spectrum of N3 also features most of the bands at closely similar frequency as the ones in the IR spectrum of N1. Thus, the presence of this isomer is also compatible with the experimental spectrum. Therefore, both N1 and N3 isomers can account for the $c i s-\left[\mathrm{PtCl}\left(\mathrm{NH}_{3}\right)_{2}\left(5^{\prime}-\mathrm{dAMP}\right)\right]^{+}$ion population and their contribution is confirmed also in this spectral range. The fact that both N3 and N1 isomers share most common calculated features also explains why discriminating between the two different fragmentation channels is not feasible in the fingerprint range. Interestingly, although N7 is favoured based on thermodynamics grounds, it appears to be the less represented in the sampled population. In fact, the agreement between the calculated spectra for this family of isomers and the experimental IRMPD spectrum is globally less good. In particular, one may note in Figure 5 that the observed band at $1648 \mathrm{~cm}^{-1}$ is instead expected at about $1628 \mathrm{~cm}^{-1}$ for all $\mathrm{N} 7$ conformers. This band combines two vibrational modes, namely the $\mathrm{NH}_{2}$ scissoring and the C6- $\mathrm{NH}_{2}$ stretching, and is well interpreted by the IR spectra of both N1 and N3 isomers, with a predicted maximum at 1646 and $1639 \mathrm{~cm}^{-1}$, respectively. Ultimately, the evidence obtained from the analysis of the experimental IRMPD spectrum in the fingerprint range suggest a dominant contribution of $\mathrm{N} 1$ and $\mathrm{N} 3$ in the sampled cis- $\left[\mathrm{PtCl}\left(\mathrm{NH}_{3}\right)_{2}\left(5^{\prime}\right.\right.$ dAMP) $]^{+}$complex, even though a minor role of N7 cannot be discarded. The observed pattern finds a counterpart in the previously reported study of the $c i s-\left[\mathrm{PtCl}\left(\mathrm{NH}_{3}\right)_{2}(\mathrm{~A})\right]^{+}$complex. ${ }^{9}$ In 
this particular complex, the presence of an iso4mer from N7 platination was excluded precisely because the band associated with the $\mathrm{NH}_{2}$ scissoring mode was expected at much lower wavenumber compared to what was found in the experimental spectrum. In that case, the gap found between the calculated and experimental features was much higher, $1602 \mathrm{~cm}^{-1}$ instead of $1658 \mathrm{~cm}^{-1} .{ }^{9}$ The present results and the formerly reported characterization of the cis- $\left[\mathrm{PtCl}\left(\mathrm{NH}_{3}\right)_{2}(\mathrm{~A})\right]^{+}$complex may be viewed from a unifying perspective if one considers that $c i s-\left[\mathrm{PtCl}\left(\mathrm{NH}_{3}\right)_{2}(\mathrm{~A})\right]^{+}$was delivered in the gas phase from the reaction of cisplatin with 5'-dAMP. It is reasonable to assume that the kinetically favoured sites of attack by cisplatin onto 5'-dAMP will be the same, either revealed on the intact cis-[PtCl( $\left.\mathrm{NH}_{3}\right)_{2}\left(5^{\prime} \text {-dAMP) }\right]^{+}$ complex presently illustrated, or in the cis-[PtCl( $\left.\left(\mathrm{NH}_{3}\right)_{2}(\mathrm{~A})\right]^{+}$fragment sampled by the ESI process. Therefore, an only modest contribution of $\mathrm{N} 7$ isomers in the assayed cis$\left[\mathrm{PtCl}\left(\mathrm{NH}_{3}\right)_{2}\left(5^{\prime}-\mathrm{dAMP}\right)\right]^{+}$complexes is consistent with the observations already reported about the simple adenine adducts. Because according to our calculations the N3 isomers are slightly less stable than the N1-N7 isomers, if the relative Gibbs free energy order obtained is correct, the significant presence of $\mathrm{N} 3$ in the $c i s-\left[\mathrm{PtCl}\left(\mathrm{NH}_{3}\right)_{2}\left(5^{\prime} \text {-dAMP }\right)\right]^{+}$population sampled in the ion trap may be a reflection of kinetic trapping of the primarily formed species from the reaction between cisplatin and 5'-dAMP. ${ }^{49,56,57}$ In a further effort to gain an insight into the process occurring in solution, we have performed additional calculations taking solvation into account through the use of the polarized continuum model (PCM). The results are reported in the Supporting Information (Table S3). Using this formalism, solvation further stabilizes the N7 isomers, confirming that thermodynamic criteria fail to justify the formation of the prevailing isomeric complexes. These finding is not new in the chemistry of platinum(II) complexes where initial, so-called metastable products tend to evolve to more stable isomers upon standing. ${ }^{58}$ According to an interesting suggestion by a referee, an alternative 
explanation for the minor contribution of the $\mathrm{N} 7$ isomer in the sampled cis- $\left[\mathrm{PtCl}\left(\mathrm{NH}_{3}\right)_{2}\left(5^{\prime}-\right.\right.$ $\mathrm{dAMP})]^{+}$population may lie in the peculiar structural features that characterize the two most stable species, N7a and N7b. Both species present the $\mathrm{PtCl}\left(\mathrm{NH}_{3}\right)_{2}$ group oriented in such a way that a facile elimination of $\mathrm{HCl}$ can take place without any adverse effect on the hydrogen bonds that stabilize these geometries. The N7 isomers could thus undergo selective depletion in the ESI process and therefore their contribution be underestimated, leaving N1b and $\mathrm{N} 3 \mathrm{a}$ as the two most thermodynamically favorable species present in the ion population. The closeness $\left(0.7 \mathrm{kJmol}^{-1}\right)$ in Gibbs energy of these two species would then be relatively consistent with a roughly 50:50 population as indicated by the kinetics experiments. Support to this hypothesis was sought by sampling the product of $\mathrm{HCl}$ loss that appears in the ESI mass spectrum, namely the cis- $\left[\mathrm{Pt}\left(\mathrm{NH}_{3}\right)_{2}\left(5^{\prime} \text {-dAMP)-H }\right]^{+}\right.$ion. However, the IRMPD spectrum reported in Figure S7 in the supporting information shows a clear N3 "signature". Additional features of lower intensity also appear in the IRMPD spectrum. They do not comply, however, with a major contribution of N7-derived species in the assayed population.

Having established that a major component in the IRMPD spectrum is due to N1 and N3 one may refer to these isomers to interpret the origin of the experimental bands as illustrated in Table S4 (Supporting Information). In particular, the pronounced band at $1271 \mathrm{~cm}^{-1}$ is related to the $\mathrm{P}=\mathrm{O}$ stretching mode combined with the umbrella mode of ammonia and various bending modes of the C'-H bond. The band at $923 \mathrm{~cm}^{-1}$ corresponds to the $\mathrm{P}-\mathrm{OH}$ stretching and bending modes expected at 922 and $925 \mathrm{~cm}^{-1}$ for $\mathrm{N} 1$ and N3, respectively, sugar ring breathing being also observed for the former. The signals detected at 958 and $1045 \mathrm{~cm}^{-1}$ may correspond to vibrational modes computed for $\mathrm{N} 1$ structures and combining $\mathrm{P}-\mathrm{OC}$ stretch with sugar ring breathing. The feature at $1100 \mathrm{~cm}^{-1}$ is the combined $\mathrm{C} 4{ }^{\prime}-\mathrm{O}$ and $\mathrm{C}^{\prime}$ '-O-P stretching modes computed at 1086 and $1120 \mathrm{~cm}^{-1}$ for N1 and N3, respectively. The small 
feature detected at $1480 \mathrm{~cm}^{-1}$ could be interpreted as adenine ring breathing and particularly the stretching of the N3-C4 bond. Finally, both N1 and N3 forms nicely reproduce the very strong signal detected above 1600 wavenumbers and dominantly associated with the $\mathrm{NH}_{2}$ scissoring mode and the stretching of the $\mathrm{C} 6=\mathrm{N}$ bond, as mentioned previously (vide supra).

\section{Conclusions}

The IRMPD spectra of the $c$ is- $\left[\mathrm{PtCl}\left(\mathrm{NH}_{3}\right)_{2}\left(5^{\prime} \text {-dAMP }\right)\right]^{+}$complex show that the sampled ionic population comprises two major isomers, characterized in the $\mathrm{X}-\mathrm{H}$ stretching region by individual resonances showing a different fragmentation pattern. Unexpectedly, the most abundant one shows coordination of platinum at the N3 position of adenine. The second one presents metal coordination at the N1 position of adenine and is slightly more stable than the N3 isomer. The negligible contribution of complexes binding the cisplatin moiety at the N7 position of adenine, in spite of being the lowest energy species, could be explained by the fact that the reaction of cisplatin with the 5'-dAMP is governed by kinetic rather than thermodynamic factors. Although sterically more hindered, the kinetically preferred platinum coordination site results to be the adenine N3. This unexpected reactivity may open the way to the synthesis of new transplatin compounds with promising performance in the formation of intrastrand cross-link between $\mathrm{N} 3$ position of adenine and the N7 position of guanine.

Interestingly, although it is commonly held that the N3 site of adenine is not favored for electrophilic attack on adenine ${ }^{11}$, there is ample recent evidence made by IRMPD action spectroscopy showing that the N3 position is in fact favored in the protonation and alkali metal cation attachment of both the free base and adenine ${ }^{9}$ DNA and RNA nucleosides ${ }^{59-61}$ and nucleotides. ${ }^{39}$

Also UVPD ${ }^{62}$ and IRMPD ${ }^{63}$ spectroscopy of alkali metal cation-adenine complexes and their hydrated forms confirm that N3 binding is preferred in a bidentate fashion with the N9 
position on the tautomer A7 and support the view that N3 attack has likely been unduly undervalued.

\section{Acknowledgements}

The authors wish to thank the CLIO team (J. M. Ortega, C. Six, G. Perilhous, J. P. Berthet) as well as P. Maître and V. Steinmetz for their support during the experiments. Financial support has been provided by the European Union (project IC007-11 entitled 'The interaction of cisplatin with nucleic acids: an approach by IRMPD spectroscopy'). A generous allocation of computing time at the Centro de Computación Científica of the Universidad Autónoma de Madrid is also acknowledged.

\section{References}

1. Rosenberg, B. Cisplatin. Chemistry and Biochemistry of a Leading Anticancer Drug. Verlag Helvetica Chimica Acta: Zürich, 1999.

2. Sherman, S. E.; Gibson, D.; Wang, A. H.; Lippard, S. J. X-Ray Structure of the Major Adduct of the Anticancer Drug Cisplatin with DNA: cis-[Pt(NH3)2(d(pGpG))]. Science 1985, 230 (4724), 412-417 DOI: 10.1126/science.4048939.

3. Sherman, S. E.; Lippard, S. J. Structural Aspects of Platinum Anticancer Drug Interactions with DNA. Chem. Rev. 1987, 87 (5), 1153-1181. DOI: 10.1021/cr00081a013

4. Sherman, S. E.; Gibson, D.; Wang, A. H. J.; Lippard, S. J. Crystal and MolecularStructure of cis-[Pt(Nh3)2(D(Pgpg))] the Principal Adduct Formed by cis-

Diamminedichloroplatinum(II) with DNA. J. Am. Chem. Soc. 1988, 110 (22), 7368-7381. DOI: $10.1021 / \mathrm{ja} 00230 \mathrm{a} 017$

5. Bancroft, D. P.; Lepre, C. A.; Lippard, S. J. Platinum-195 NMR Kinetic and Mechanistic Studies of cis- and trans-Diamminedichloroplatinum(II) Binding to DNA. J. Am. Chem. Soc. 1990, 112 (19), 6860-6871. DOI: 10.1021/ja00175a020

6. Fichtinger-Schepman, A. M.; van der Veer, J. L.; den Hartog, J. H.; Lohman, P. H.; Reedijk, J. Adducts of the Antitumor Drug cis-Diamminedichloroplatinum(II) with DNA: Formation, Identification, and Quantitation. Biochemistry 1985, 24 (3), 707-13. DOI: 10.1021/bi00324a025

7. Reily, M. D.; Marzilli, L. G. Novel, Definitive NMR Evidence for N(7), alpha-PO4 Chelation of 6-Oxopurine Nucleotide Monophosphates to Platinum Anticancer Drugs $J$. Am. Chem. Soc. 1986, 108 (26), 8299-8300 DOI: 10.1021/ja00286a049.

8. Reily, M. D.; Hambley, T. W.; Marzilli, L. G. Macrochelate Complexes of Purine 5'Nucleotide Triphosphates and Monophosphates. Definitive Multinuclear NMR Evidence 
Supported by Molecular Mechanics Calculations. J. Am. Chem. Soc. 1988, 110 (10), 29993007 DOI: 10.1021/ja00218a001.

9. Chiavarino, B.; Crestoni, M. E.; Fornarini, S.; Scuderi, D.; Salpin, J. Y. Interaction of Cisplatin with Adenine and Guanine: a Combined IRMPD, MS/MS, and Theoretical Study. $J$. Am. Chem. Soc. 2013, 135 (4), 1445-1455 DOI: 10.1021/ja309857d.

10. Chiavarino, B.; Crestoni, M. E.; Fornarini, S.; Scuderi, D.; Salpin, J.-Y. Interaction of Cisplatin with 5 '-dGMP: a Combined IRMPD and Theoretical Study. Inorg. Chem. 2015, 54 (7), 3513-3522 DOI: 10.1021/acs.inorgchem.5b00070.

11. Štarha, P.; Vančo, J.; Trávníček, Z. Platinum Complexes Containing Adenine-Based Ligands: An Overview Of Selected Structural Features. Coord. Chem. Rev. 2017, 332, 1-29. DOI: http://dx.doi.org/10.1016/j.ccr.2016.09.017.

12. Corinti, D.; Coletti, C.; Re, N.; Chiavarino, B.; Crestoni, M. E.; Fornarini, S. Cisplatin Binding To Biological Ligands Revealed at the Encounter Complex Level by IR Action Spectroscopy. Chemistry - A European Journal 2016, 22 (11), 3794-3803 DOI: 10.1002/chem.201504521.

13. De Petris, A.; Ciavardini, A.; Coletti, C.; Re, N.; Chiavarino, B.; Crestoni, M. E.; Fornarini, S. Vibrational Signatures of the Naked Aqua Complexes from Platinum(II) Anticancer Drugs. J. Phys. Chem. Lett. 2013, 4 (21), 3631-3635 DOI: 10.1021/jz401959s.

14. MacAleese, L.; Maitre, P. Infrared Spectroscopy of Organometallic Ions in the Gas Phase: from Model to Real World Complexes. Mass Spectrom. Rev. 2007, 26 (4), 583-605. DOI: $10.1002 / \mathrm{mas} .20138$

15. Eyler, J. R. Infrared Multiple Photon Dissociation Spectroscopy of Ions in Penning Traps. Mass Spectrom. Rev. 2009, 28 (3), 448-467. DOI: 10.1002/mas.20217

16. Fridgen, T. D. Infrared Consequence Spectroscopy of Gaseous Protonated and Metal Ion Cationized Complexes. Mass Spectrom. Rev. 2009, 28 (4), 586-607.

DOI: $10.1002 / \mathrm{mas} .20224$

17. Polfer, N. C. Infrared Multiple Photon Dissociation Spectroscopy of Trapped Ions. Chem. Soc. Rev. 2011, 40 (5), 2211-2221 DOI: 10.1039/c0cs00171f.

18. Sinha, R. K.; Maitre, P.; Piccirillo, S.; Chiavarino, B.; Crestoni, M. E.; Fornarini, S. Cysteine Radical Cation: a Distonic Structure Probed by Gas Phase IR Spectroscopy. Phys. Chem. Chem. Phys. 2010, 12 (33), 9794-9800 DOI: 10.1039/c003576a.

19. Chiavarino, B.; Crestoni, M.E.; Fornarini, S.; Taioli, S.; Mancini, I.; Tosi, P. Infrared Spectroscopy of Copper-Resveratrol Complexes: a Joint Experimental and Theoretical Study Journal of Chemical Physics, 2012, 137 (2), art. no. 024307. DOI: 10.1063/1.4732583

20. Lemaire, J.; Boissel, P.; Heninger, M.; Mauclaire, G.; Bellec, G.; Mestdagh, H.; Simon, A.; Le Caer, S.; Ortega, J. M.; Glotin, F.; Maitre, P. Gas Phase Infrared Spectroscopy of Selectively Prepared Ions. Phys. Rev. Lett. 2002, 89, 273002-1. DOI: https://doi.org/10.1103/PhysRevLett.89.273002

21. Bakker, J. M.; Besson, T.; Lemaire, J.; Scuderi, D.; Maitre, P. Gas-Phase Structure of a $\pi$-Allyl-Palladium Complex: Efficient Infrared Spectroscopy in a $7 \mathrm{~T}$ Fourier Transform Mass Spectrometer. J. Phys. Chem. A 2007, 111 (51), 13415-13424. DOI: 10.1021/jp074935e 
22. Lee, C.; Yang, W.; Parr, R. G. Development of the Colle-Salvetti Correlation-Energy Formula into a Functional of the Electron Density. Physical Reviews B 1988, 37 (2), 785-789. DOI: https://doi.org/10.1103/PhysRevB.37.785

23. Becke, A. D. Density-Functional Thermochemistry. III. The Rrole of Exact Exchange. J. Chem. Phys. 1993, 98, 5648-5652. DOI: http://dx.doi.org/10.1063/1.464913

24. Frisch, M. J.; al., e. Gaussian09, Revision C.01. See Supporting Information for complete citation.

25. Hay, P. J.; Wadt, W. R. Ab Initio Effective Core Potentials for Molecular Calculations. Potentials for the Transition-Metal Atoms Sc to Hg. J. Chem. Phys. 1985, 82 (1), 270-283. DOI: http://dx.doi.org/10.1063/1.448799

26. Hay, P. J.; Wadt, W. R. Ab Initio Efective Core Potentials for Molecular Calculations. Potentials for K To Au Iincluding the Outermost Core Orbitals. J. Chem. Phys. 1985, 82 (1), 299-310. DOI: http://dx.doi.org/10.1063/1.448975

27. Wadt, W. R.; Hay, P. J. Ab Initio Effective Core Potentials for Molecular Calculations. Potentials for Main Group Elements Na to Bi. J. Chem. Phys. 1985, 82 (1), 284298. DOI: http://dx.doi.org/10.1063/1.448975

28. Stevens, W. J.; Krauss, M.; Basch, H.; Jasien, P. G. Relativistic Compact Effective Potentials and Efficient, Shared-Exponent Basis-Sets for the Third-, Fourth-, and Fifth-Row Atoms. Can. J. Chem. 1992, 70 (2), 612-630. DOI. 10.1139/v92-085

29. Fales, B. S.; Fujamade, N. O.; Nei, Y. W.; Oomens, J.; Rodgers, M. T. Infrared Multiple Photon Dissociation Action Spectroscopy and Theoretical Studies of Diethyl Phosphate Complexes: Effects of Protonation and Sodium Cationization on Structure. J. Am. Soc. Mass Spectrom. 2011, 22 (1), 81-92 DOI: 10.1007/s13361-010-0007-6.

30. Fales, B. S.; Fujamade, N. O.; Oomens, J.; Rodgers, M. T. Infrared Multiple Photon Dissociation Action Spectroscopy and Theoretical Studies of Triethyl Phosphate Complexes: Effects of Protonation and Sodium Cationization on Structure. J. Am. Soc. Mass Spectrom. 2011, 22 (10), 1862-1871 DOI: 10.1007/s13361-011-0208-7.

31. Sharma, A.; Ohanessian, G.; Clavaguera, C. Accuracy of density functionals in the description of dispersion interactions and IR spectra of phosphates and phosphorylated compounds. Journal of Molecular Modeling 2014, 20 (9), DOI: 10.1007/s00894-014-2426-y.

32 Correia, C. F.; Balaj, P. O.; Scuderi, D.; Maitre, P.; Ohanessian, G. Vibrational signatures of protonated, phosphorylated amino acids in the gas phase. J. Am. Chem. Soc. 2008, 130 (11), 3359-3370.

33. Correia, C. F.; Clavaguera, C.; Erlekam, U.; Scuderi, D.; Ohanessian, G. IRMPD Spectroscopy of a Protonated, Phosphorylated Dipeptide. ChemPhysChem 2008, 9 (17), 25642573 DOI: $10.1002 /$ cphc. 200800469.

34. Scuderi, D.; Correia, C. F.; Balaj, O. P.; Ohanessian, G.; Lemaire, J.; Maitre, P. Structural Characterization by IRMPD Spectroscopy and DFT Calculations of Deprotonated Phosphorylated Amino Acids in the Gas Phase. ChemPhysChem 2009, 10 (9-10), 1630-1641.

35. Chiavarino, B.; Crestoni, M. E.; Fornarini, S.; Lanucara, F.; Lemaire, J.; Maitre, P.; Scuderi, D. Infrared spectroscopy of isolated nucleotides 1 . The cyclic 3 ',5'-adenosine monophosphate anion. Int. J. Mass Spectrom. 2008, 270 (3), 111-117. 
36. Nei, Y. w.; Hallowita, N.; Steill, J. D.; Oomens, J.; Rodgers, M. T. Infrared Multiple Photon Dissociation Action Spectroscopy of Deprotonated DNA Mononucleotides: GasPhase Conformations and Energetics. J. Phys. Chem. A 2013, 117 (6), 1319-1335 DOI: 10.1021/jp3077936.

37. Nei, Y. W.; Crampton, K. T.; Berden, G.; Oomens, J.; Rodgers, M. T. Infrared Multiple Photon Dissociation Action Spectroscopy of Deprotonated RNA Mononucleotides: Gas-Phase Conformations and Energetics. J. Phys. Chem. A 2013, 117 (41), 10634-10649 DOI: $10.1021 / \mathrm{jp} 4039495$.

38. Lanucara, F.; Crestoni, M. E.; Chiavarino, B.; Fornarini, S.; Hernandez, O.; Scuderi, D.; Maitre, P. Infrared Spectroscopy of Nucleotides in the Gas Phase 2. The Protonated Cyclic 3 ',5 '-Adenosine Monophosphate. RSC Adv. 2013, 3 (31), 12711-12720 DOI: $10.1039 / \mathrm{c} 3 \mathrm{ra} 41117 \mathrm{f}$.

39. Wu, R. R.; He, C. C.; Hamlow, L. A.; Nei, Y. W.; Berden, G.; Oomens, J.; Rodgers, M. T. N3 Protonation Induces Base Rotation of 2 '-Deoxyadenosine-5 '-monophosphate and Adenosine-5 '-monophosphate. J. Phys. Chem. B 2016, 120 (20), 4616-4624 DOI: 10.1021/acs.jpcb.6b04052.

40. Ligare, M.R.; Rijs, A.M.; Berden, G.; Kabeláč, M.; Nachtigallova, D.; Oomens, J.; De Vries, M.S. Resonant Infrared Multiple Photon Dissociation Spectroscopy of Anionic Nucleotide Monophosphate Clusters Journal of Physical Chemistry B , 2015, Volume 119, , Pages 7894-7901 DOI: $10.1021 /$ acs.jpcb.5b02222

41. Chiavarino, B.; Crestoni, M. E.; Fornarini, S.; Lemaire, J.; Maitre, P.; MacAleese, L. pi-complex structure of gaseous benzene-NO cations assayed by IR multiple photon dissociation spectroscopy. J. Am. Chem. Soc. 2006, 128 (38), 12553-12561.

42. Coletti, C.; Re, N.; Scuderi, D.; Maitre, P.; Chiavarino, B.; Fornarini, S.; Lanucara, F.; Sinha, R. K.; Crestoni, M. E. IRMPD spectroscopy of protonated S-nitrosocaptopril, a biologically active, synthetic amino acid. Phys. Chem. Chem. Phys. 2010, 12 (41), 1345513467.

43. Lanucara, F.; Chiavarino, B.; Crestoni, M. E.; Scuderi, D.; Sinha, R. K.; Maitre, P.; Fornarini, S. Naked Five-Coordinate Fe-III(NO) Porphyrin Complexes: Vibrational and Reactivity Features. Inorg. Chem. 2011, 50 (10), 4445-4452 DOI: 10.1021/ic200073v.

44. Paciotti, R.; Coletti, C.; Re, N.; Scuderi, D.; Chiavarino, B.; Fornarini, S.; Crestoni, M. E. Serine O-sulfation probed by IRMPD spectroscopy. Phys. Chem. Chem. Phys. 2015, 17 (39), 25891-25904 DOI: 10.1039/c5cp01409c.

45. Scuderi, D.; Bodo, E.; Chiavarino, B.; Fornarini, S.; Crestoni, M. E. Amino Acid Oxidation: A Combined Study of Cysteine Oxo Forms by IRMPD Spectroscopy and Simulations. Chemistry - A European Journal 2016, 22 (48), 17239-17250 DOI: 10.1002/chem.201603298.

46. Prell, J. S.; O'Brien, J. T.; Williams, E. R. IRPD Spectroscopy and Ensemble Measurements: Effects of Different Data Acquisition and Analysis Methods. J. Am. Soc. Mass Spectrom. 2010, 21 (5), 800-809. DOI: http://dx.doi.org/10.1016/j.jasms.2010.01.010

47. Prell, J. S.; Chang, T. M.; Biles, J. A.; Berden, G.; Oomens, J.; Williams, E. R. Isomer Population Analysis of Gaseous Ions from Infrared Multiple Photon Dissociation Kinetics. $J$. Phys. Chem. A 2011, 115 (13), 2745-2751 DOI: 10.1021/jp2004166. 
48. Prell, J. S.; Chang, T. M.; O’Brien, J. T.; Williams, E. R. Hydration Isomers of Protonated Phenylalanine and Derivatives: Relative Stabilities from Infrared Photodissociation. J. Am. Chem. Soc. 2010, 132 (22), 7811-7819 DOI: 10.1021/ja102765w.

49. Hernandez, O.; Paizs, B.; Maitre, P. Rearrangement Chemistry of a(n) Ions Probed by IR Spectroscopy. Int. J. Mass Spectrom. 2015, 377, 172-178 DOI:10.1016/j.ijms.2014.08.008.

50. Corinti, D.; De Petris, A.; Coletti, C.; Re, N.; Chiavarino, B.; Crestoni, M. E.;

Fornarini, S. Cisplatin Primary Complex with 1-Histidine Target Revealed by IR Multiple Photon Dissociation (IRMPD) Spectroscopy. ChemPhysChem 2017, 18 (3), 318-325 DOI: 10.1002/cphc.201601172.

51. Patrick, A. L.; Cismesia, A. P.; Tesler, L. F.; Polfer, N. C. Effects of ESI Conditions on Kinetic Trapping of the Solution-Phase Protonation Isomer of p-Aminobenzoic Acid in the Gas Phase. Int. J. Mass Spectrom., DOI: http://dx.doi.org/10.1016/j.ijms.2016.09.022.

52. Broquier, M.; Lahmani, F.; Zehnacker-Rentien, A.; Brenner, V.; Millié, P.; Peremans, A. Hydrogen-Bonded Bridges in Complexes of o-Cyanophenol: Laser-Induced Fluorescence and IR/UV Double-Resonance Studies. The Journal of Physical Chemistry A 2001, 105 (28), 6841-6850 DOI: 10.1021/jp010218n.

53. Bakker, J. M.; Sinha, R. K.; Besson, T.; Brugnara, M.; Tosi, P.; Salpin, J. Y.; Maitre, P. Tautomerism of Uracil Probed via Infrared Spectroscopy of Singly Hydrated Protonated Uracil. J. Phys. Chem. A 2008, 112 (48), 12393-12400. DOI: 10.1021/jp806396t

54. Bakker, J. M.; Salpin, J. Y.; Maitre, P. Tautomerism of Cytosine Probed by Gas Phase IR Spectroscopy. Int. J. Mass Spectrom. 2009, 283 (1-3), 214-221. DOI: 10.1016/j.ijms.2009.03.014

55. Mackeprang, K.; Kjaergaard, H. G.; Salmi, T.; Hänninen, V.; Halonen, L. The Effect of Large Amplitude Motions on The Transition Frequency Redshift in Hydrogen Bonded Complexes: a Physical Picture. The Journal of Chemical Physics 2014, 140 (18), 184309 DOI: $10.1063 / 1.4873420$.

56. Zehnacker, A. Chirality Effects in Gas-Phase Spectroscopy and Photophysics of Molecular and Ionic Complexes: Contribution of Low and Room Temperature Studies. International Reviews in Physical Chemistry 2014, 33 (2), 151-207 DOI:

10.1080/0144235X.2014.911548.

57. Voronina, L.; Rizzo, T. R. Spectroscopic Studies of Kinetically Trapped Conformations in the Gas Phase: the Case of Triply Protonated Bradykinin. Phys. Chem. Chem. Phys. 2015, 17 (39), 25828-25836 DOI: 10.1039/C5CP01651G.

58. Appleton, T. G. Donor Atom Preferences in Complexes of Platinum and Palladium with Amino Acids and Related Molecules. Coord. Chem. Rev. 1997, 166, 313-359 DOI: http://dx.doi.org/10.1016/S0010-8545(97)00047-7.

59. Wu, R.R.; Yang, B.; Berden, G.; Oomens, J. ; Rodgers, M.T. Gas-phase conformations and energetics of protonated 2'-deoxyadenosine and adenosine: IRMPD action spectroscopy and theoretical studies. Journal of Physical Chemistry B 5, 2015, 119, 2795-2805 DOI: $10.1021 / j p 509267 \mathrm{k}$

60 Zhu, Y.; Hamlow, L.A.; He, C.C. ; Strobehn, S.F. ; Lee, J.K. ; Gao, J.; Berden, G. ; Oomens, J.; Rodgers, M. T. Influence of Sodium Cationization versus Protonation on the Gas- 
Phase Conformations and Glycosidic Bond Stabilities of 2'-Deoxyadenosine and Adenosine. Journal of Physical Chemistry B , 2016 ,120, 8892-8904 DOI: 10.1021/acs.jpcb.6b06105

61. Wu, R. R.; Rodgers, M.T. Mechanisms and energetics for: N -glycosidic bond cleavage of protonated adenine nucleosides: N3 protonation induces base rotation and enhances $\mathrm{N}$ glycosidic bond stability. Physical Chemistry Chemical Physics, 2016, 18, 16021-16032 DOI: $10.1039 / \mathrm{c} 6 \mathrm{cp} 01445 \mathrm{c}$

62. Baek, J.Y.; Choi, C.M.; Eun, H.J.; Park, K.S.; Choi, M.C.; Heo, J.; Kim, N.J. Ultraviolet photodissociation spectroscopy of cold, isolated adenine complexes with a potassium cation. Chemical Physics Letters, 2015, 635, 163-167 DOI: 10.1016/j.cplett.2015.06.045

63. Rajabi, K.;Gillis, E.A.L.; Fridgen, T.D. Structures of alkali metal ion-adenine complexes and hydrated complexes by IRMPD spectroscopy and electronic structure calculations. Journal of Physical Chemistry A , 2010, Volume 114, 3449-3456 DOI: 10.1021/jp9098683

\section{Captions for Figures}


Figure 1. Chemical structure of 2'-deoxyadenosine-5'-monophosphate.

Figure 2. Experimental IRMPD spectrum of the cis-[PtCl( $\left.\mathrm{NH}_{3}\right)_{2}\left(5^{\prime} \text {-dAMP) }\right]^{+}$complex (bottom) in the $\mathrm{X}-\mathrm{H}(\mathrm{X}=\mathrm{C}, \mathrm{N}, \mathrm{O})$ stretch region compared to IR spectra of exemplary isomers computed at the B3LYP/ 6-311G** level. See text for details.

Figure 3. Mass spectrum following selection of the isotopic cluster at $\mathrm{m} / \mathrm{z} 594-598$, cis$\left[\mathrm{PtCl}\left(\mathrm{NH}_{3}\right)_{2}\left(5^{\prime} \text {-dAMP }\right)\right]^{+}$recorded after irradiation by IR light at a) $3663 \mathrm{~cm}^{-1}$ b) $3493 \mathrm{~cm}^{-1}$ c) $3435 \mathrm{~cm}^{-1}$. The insets present enlarged portions of the mass spectrum.

Figure 4. Decay of the precursor cis- $\left[\mathrm{PtCl}\left(\mathrm{NH}_{3}\right)_{2}\left(5^{\prime}-\mathrm{dAMP}\right)\right]^{+}$ion abundance plotted as a function of irradiation time. For each selected wavenumber, the equation of the fitting exponential decay is reported.

Figure 5. Experimental IRMPD spectrum of the cis-[PtCl$\left.\left(\mathrm{NH}_{3}\right)_{2}\left(5^{\prime}-\mathrm{dAMP}\right)\right]^{+}$complex (bottom) in the fingerprint range compared to the IR spectra of exemplary isomers computed at the B3LYP/ 6-311G** level. See text for details. 


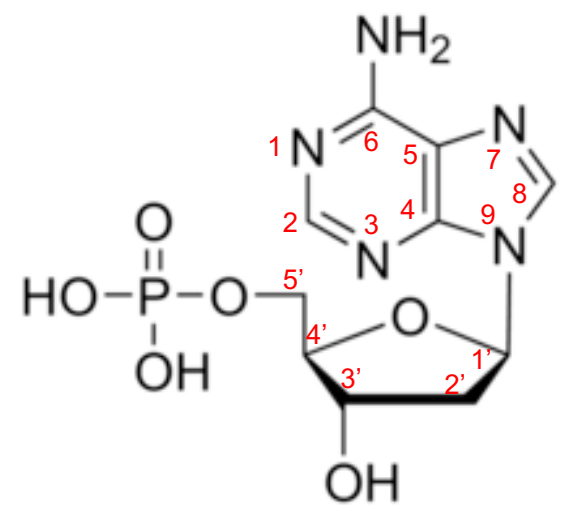

Figure 1. Chemical structure of 2'-deoxyadenosine-5'-monophosphate. 


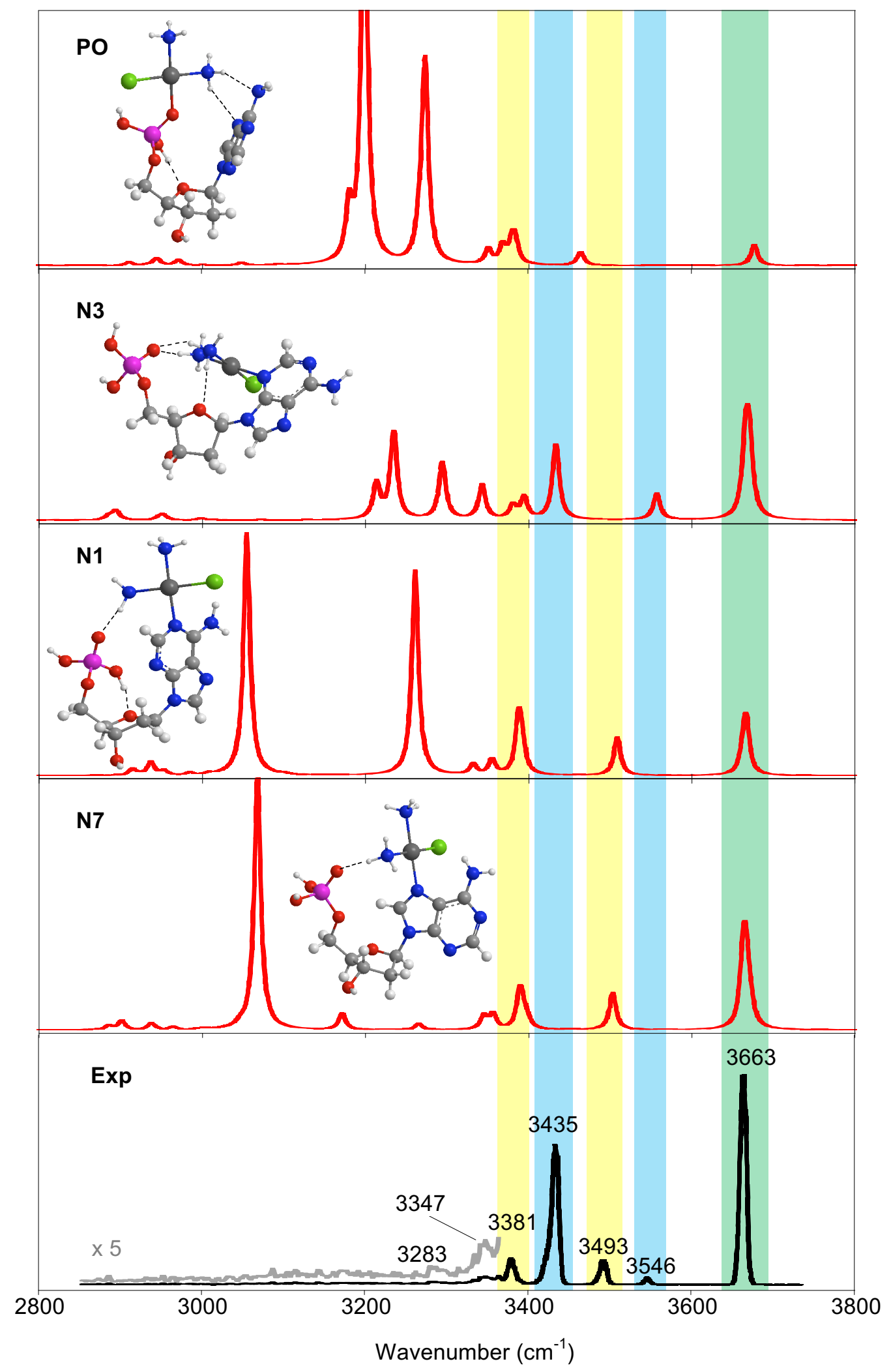

Figure 2. Experimental IRMPD spectrum of the cis-[PtCl$\left.\left(\mathrm{NH}_{3}\right)_{2}\left(5^{\prime}-\mathrm{dAMP}\right)\right]^{+}$complex (bottom) in $\mathrm{X}-\mathrm{H}(\mathrm{X}=\mathrm{C}, \mathrm{N}, \mathrm{O})$ stretch region compared to IR spectra of exemplary isomers computed at the B3LYP/ 6-311G** level. See text for details. 

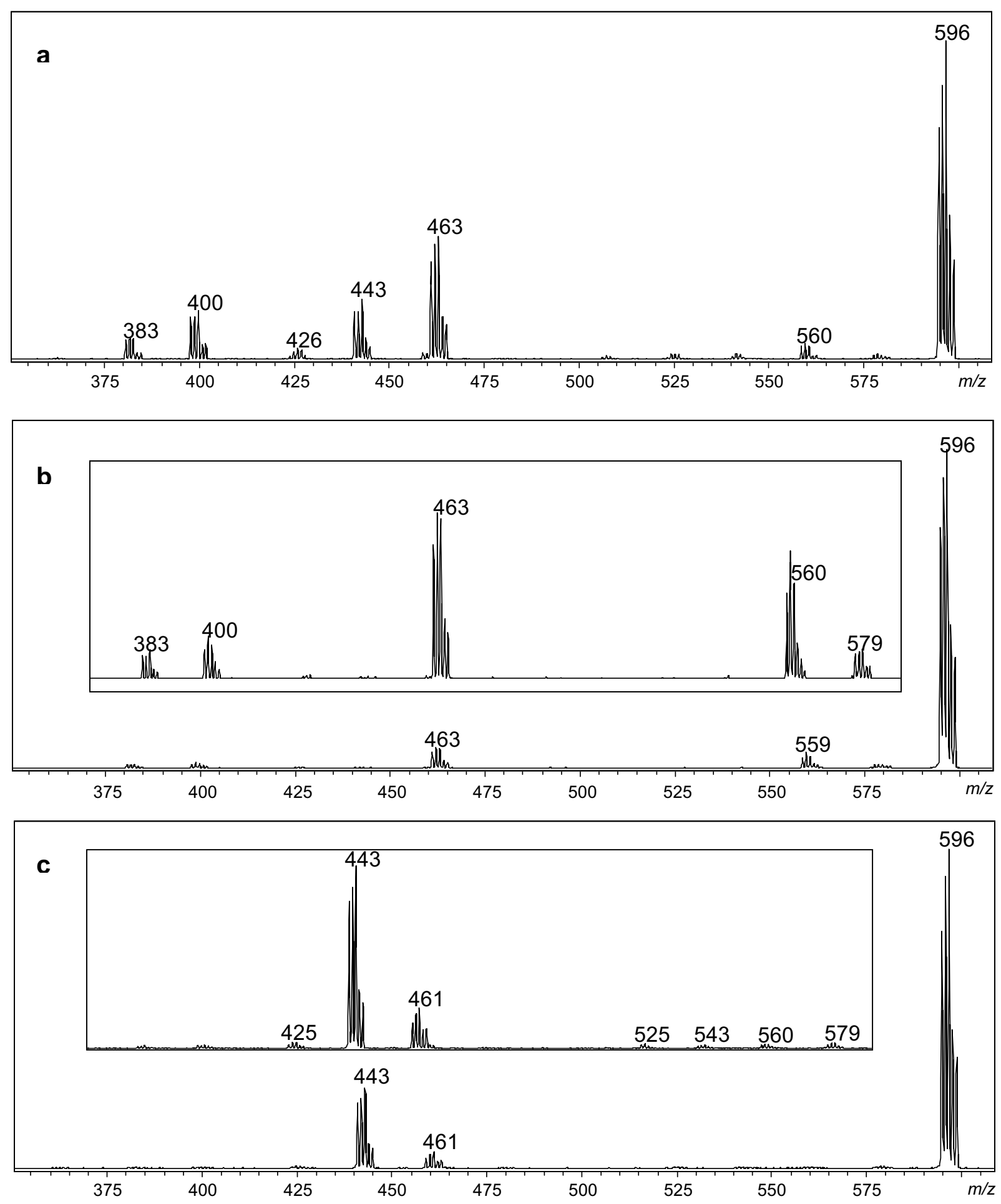

Figure 3. Mass spectrum following selection of the isotopic cluster at $\mathrm{m} / \mathrm{z} 594-598$, cis$\left[\mathrm{PtCl}\left(\mathrm{NH}_{3}\right)_{2}\left(5^{\prime}-\mathrm{dAMP}\right)\right]^{+}$recorded after irradiation by IR light at a) $3663 \mathrm{~cm}^{-1}$ b) $3493 \mathrm{~cm}^{-1}$ c) $3435 \mathrm{~cm}^{-1}$. The insets present enlarged portions of the mass spectrum. 


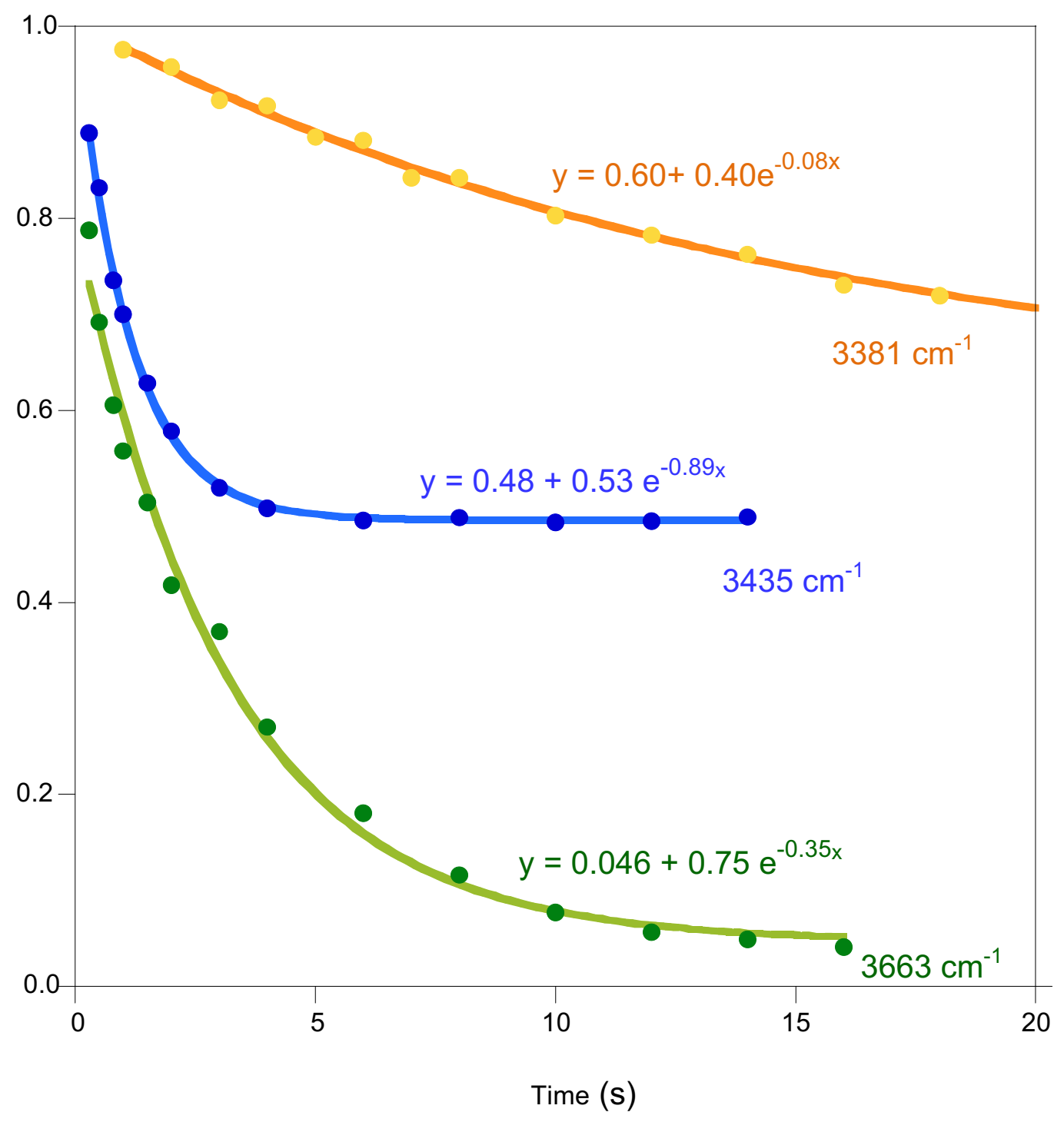

Figure 4. Decay of the precursor cis-[PtCl$\left.\left(\mathrm{NH}_{3}\right)_{2}\left(5^{\prime}-\mathrm{dAMP}\right)\right]^{+}$ion abundance plotted as a function of irradiation time. For each selected wavenumber, the equation of the fitting exponential decay is reported. 


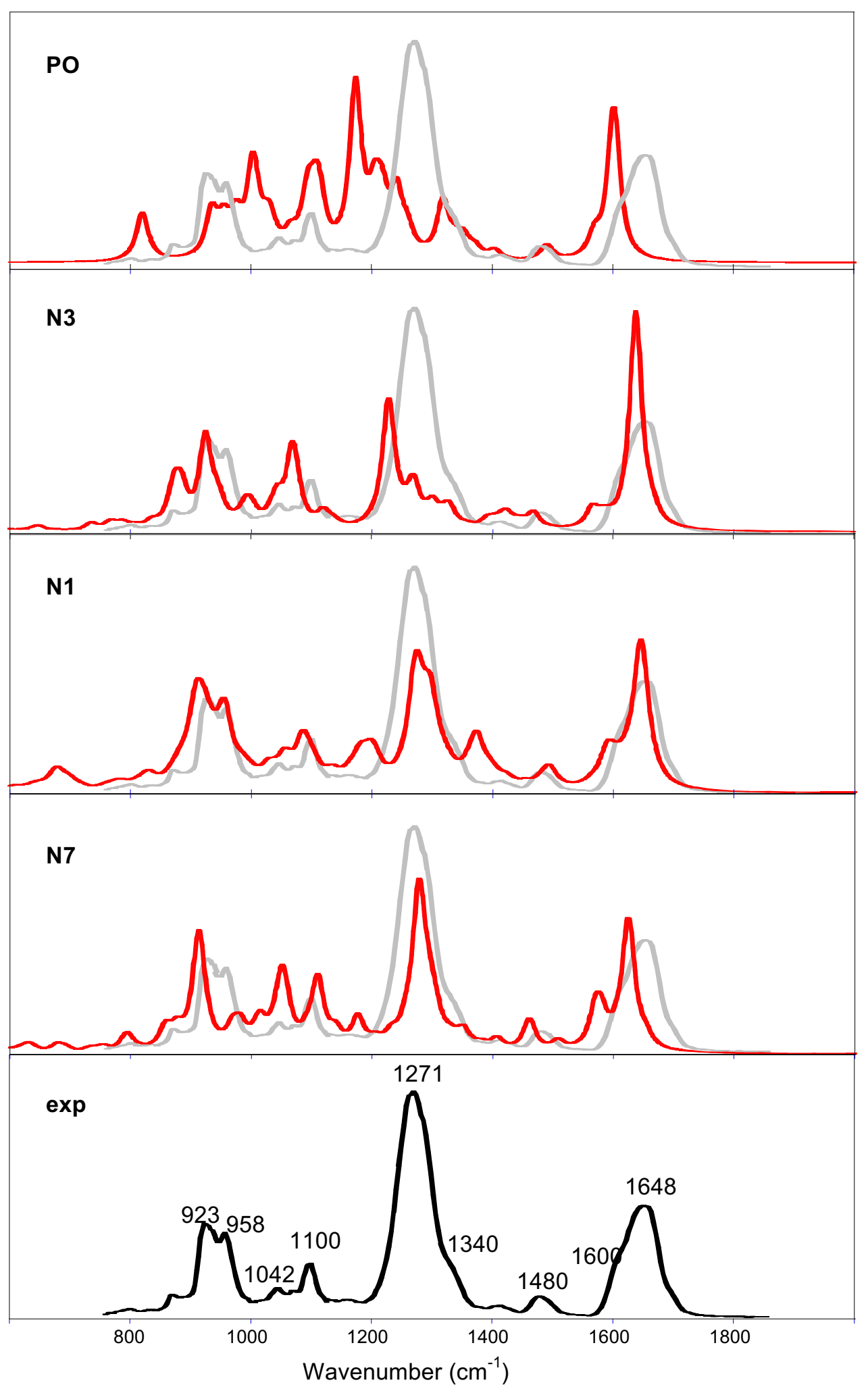

Figure 5. Experimental IRMPD spectrum of the cis-[PtCl$\left.\left(\mathrm{NH}_{3}\right)_{2}\left(5^{\prime}-\mathrm{dAMP}\right)\right]^{+}$complex (bottom) in the fingerprint range compared to the IR spectra of exemplary isomers computed at the B3LYP/ 6-311G** level. See text for details. 


\section{Table of Contents Synopsis and Graphic}

Synopsis: The gas-phase structures of the species obtained by the reaction of cisplatin and 2'deoxyadenosine-5'-monophosphate (5'-dAMP) are investigated by infrared multiple photon dissociation (IRMPD) action spectroscopy combined with quantum chemical calculations. IRMPD kinetics experiments indicate that the most abundant component in the sampled cis$\left[\mathrm{PtCl}\left(\mathrm{NH}_{3}\right)_{2}\left(5^{\prime}-\mathrm{dAMP}\right)\right]^{+}$ion population is the isomer platinated at the $\mathrm{N} 3$ position of adenine, in spite of being the less stable one among the potential candidates.

"For Table of Contents Only"

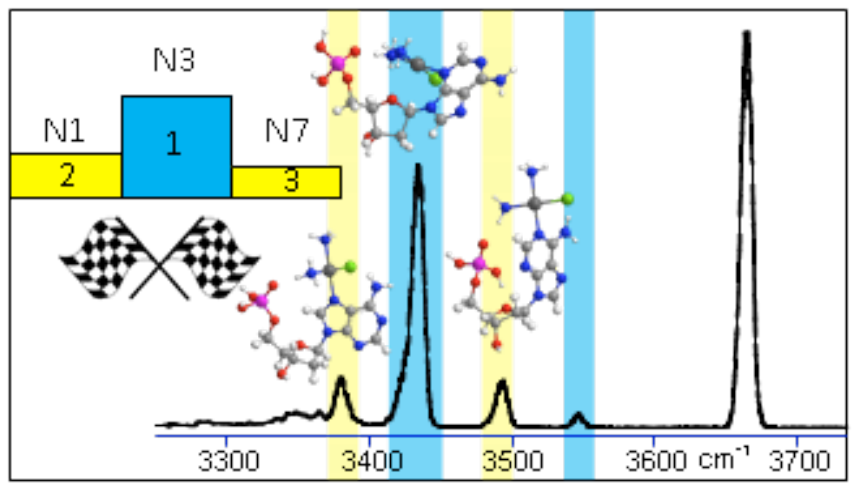

